\title{
Evaluation of epoxy modification in asphalt mastic
}

\author{
Panos Apostolidis (1D - Xueyan Liu • Paul Marocho • Martin van de Ven • \\ Sandra Erkens $\cdot$ Tom Skarpas
}

Received: 24 January 2020/Accepted: 12 May 2020/Published online: 15 September 2020

(C) The Author(s) 2020

\begin{abstract}
In-depth understanding of the synergetic effect between the various incorporating constituents in asphalt binders (e.g., polymers, fillers) is needed to design durable paving materials with desired properties. In this research, the focus was first on the effect of the reactivity of fillers on the evolution of adhesive strength between stone aggregates and epoxy modified asphalt mastics during the epoxy polymerization. Uniaxial tensile tests were performed on different combinations of fillers and binders with and without the epoxy-based polymer, and at different modification levels. Based on the results of the tensile tests, the increase of the adhesive strength of mastic with aggregates was generally lower when reactive filler particles (i.e., hydrated lime) were added than of epoxy binders with non-reactive filler. In other words, the non-reactive fillers did not influence the adhesion process and were thus selected for the next step studies on aging. The chemo-mechanical changes of epoxy modified asphalt mastics were analysed after pressure
\end{abstract}

P. Apostolidis $(\bowtie) \cdot X$. Liu · P. Marocho .

M. van de Ven · S. Erkens - T. Skarpas

Section of Pavement Engineering, Faculty of Civil

Engineering and Geosciences, Delft University of

Technology, Delft, Netherlands

e-mail: p.apostolidis@tudelft.nl

T. Skarpas

Department of Civil Infrastructure and Environmental Engineering, Khalifa University of Science and

Technology, Abu Dhabi, United Arab Emirates aging vessel and oven-conditioning after various aging times by means of Fourier transform infrared spectroscopy and dynamic shear rheometer. Less sulfoxides formed and higher modulus levels were measured with increasing the epoxy polymer in mastics over oven- and PAV-aging conditions. Due to the pressure difference, the rate of modulus increases and phase angle decrease was higher when the materials were conditioned in PAV than in oven.

Keywords Epoxy asphalt - Asphalt binder . Bitumen · Filler · Aging · Long-life pavement

\section{Introduction}

Asphalt binder, which is a petroleum derivative, is the most widely used binding material in pavement structures. With the continuously increasing costs to maintain high quality infrastructure, the implementation of new technologies has become top priority for road agencies all over the world. New or relatively new materials, such as epoxy-based polymers in asphalt binders, are attracting the interest of the international pavement engineering community.

In comparison with the thermoplastic block copolymers, epoxy-based polymers are thermosetting and thus remain at solid state when they are fully polymerized. The modification of asphalt binders with epoxy-based polymers is well-recognized, among 
others, because of their high resistance against fracture [1-7] with various applications on steel deck bridges, airfields and roadways [8-13]. Nevertheless, a general lack of knowledge exists about the impact of epoxybased polymers on the long-term oxidative aging performance of asphaltic materials. Moreover, no research has been done on the influence of different filler types on the efficiency of epoxy-based polymers as added agents for long-lasting asphalt pavements. Different phenomena take place when reactive polymers are incorporated in asphalt and their contribution to long-term oxidative aging resistance could be linked with other reactive constituents in asphalt, such as fillers.

\section{Background}

Until now, most of the research is focused on the impact of aging on the chemistry of the asphalt binder and the chemo-mechanical changes associated with the aging in binders [14-17]. It is well known that the complexity of aging increases when polymer modification, such as styrene-butadiene-styrene, are incorporated in asphalt binders. Moreover, oxidative aging can cause substantial changes in the chemistry of interface between asphalt binder and mineral particles. Therefore, the aging of asphalt mixes is influenced by the individual constituents and their mutual interactions.

The chemistry of an asphalt binder changes due to oxidative aging and thus determines their performance. Aging is recognized as a chemically induced hardening process during the asphalt production (i.e., short-term aging) and during the service life of asphalt pavement structures (i.e., long-term aging). Therefore, the chemistry of binder is very important for the final quality. The chemical composition of asphalt primarily depends on its crude oil source and processing, and it strongly influences the chemical reactivity and mechanical properties of asphalt binders. Based on differences in solubility and polarity, asphalt binders can be separated into four primary chemical classes: saturates, aromatics, resins, and asphaltenes. During oxidative aging, a decrease in aromatic content together with a higher asphaltene content is caused. In mechanics, oxidative aging is accompanied by stiffening (i.e., modulus increase) and embrittlement of the binder, of which the low temperature changes in general contribute to the deterioration of asphalt pavements.

Apart from binders, the binding system between the mineral particles in asphalt mixes (i.e., asphalt mastic) includes also very fine particles, named fillers. Reactive (with binder) fillers, such as hydrated lime, are being used in asphalt mixes for many years, because of their positive influence on the performance of mastics. It has been proven that the addition of hydrated lime improves the resistance against moisture-induced damage $[18,19]$ and increases the fracture toughening in asphalt mixes [20-24]. In addition, extended studies on the impact of hydrated lime on aging demonstrated a reduction on the oxidation rate and subsequently improvement on the aging resistance [25-31]. Studies demonstrated improvements in aging resistance of neat binders performing experiments at temperatures (much) higher than pavement temperatures in the field (e.g., $100-150{ }^{\circ} \mathrm{C}$ ) [25-29] or at high pavement temperatures (e.g., $60{ }^{\circ} \mathrm{C}$ ) [30, 31].

Several physical and chemical processes govern the effect of mineral fillers during oxidative aging of binders and the reactivity of some components on the surface of fillers possibly are able to catalyse the oxidation of asphalt [32]. From the chemical point of view, adsorption of polar asphaltic compounds (i.e., asphaltenes) onto mineral particles is much larger than for other compounds, less polar (i.e., resins) or nonpolar (i.e., aromatics and saturates) [15]. Potentially, particles with a high surface area adsorb more polar compounds. Particles with low adsorption of highly polar fractions exhibit the greatest catalytic effect during the oxidative aging of asphalt binder, while the smallest effect is observed for particles with a high adsorption [22]. A study indicated that during aging the presence of mineral particles delays the increase of modulus of binders compared with neat binders for equivalent age periods [33]. The reduced oxidation rate may be caused by adsorption of polar functional groups of binders on the surface of minerals. Even the fact that the rate and the level of long-term oxidative aging were equal for binders with lime, lime could be able to adsorb polar functional groups of asphalt binders $[25,26]$. 


\section{Motivation and objectives}

The inclusion of polymeric structures, such as epoxybased polymers, in asphalt mastics increases the complexity of the long-term oxidative aging studies. Also, the potential of competitive interaction of epoxy polymeric structures with reactive fillers, as hydrated lime, in binder may reduce the interaction between the two constituents and reduce their potential benefits. Thus, special attention is given to assessing the synergetic effect of filler with the polymer on the bonding strength at the aggregate surface interface. A lot of research has demonstrated the benefits of fillers in binders but no studies are available on the influence of fillers on epoxy binders (EB) yet. This research was designed to investigate the effect of epoxy on a mastic with two different filler types. After various oxidative aging times, mechanical properties and chemical composition changes of filler-including EBs (EBFs) as a function of aging time were studied and compared with control materials. The aging was performed both in pressure-aging vessel (PAV) and oven.

\section{Materials and methods}

\subsection{Materials preparation}

Two commercially available of types of filler passing through the 0.075-mm sieve were used. Both filler types were mineral particles, composed of limestone. The reactive filler, named RF (density: $2.550 \mathrm{~g} / \mathrm{cm}^{3}$; BET specific surface area: $8.51 \mathrm{~m}^{2} / \mathrm{g}$ ), was limestone (calcium carbonate) with a certain amount of hydrated lime (calcium hydroxide), approximately $20 \%$. The non-reactive filler, named NRF (density: $2.767 \mathrm{~g} / \mathrm{cm}^{3}$; BET specific surface area: $13.25 \mathrm{~m}^{2} / \mathrm{g}$ ), was the same particle as RF but without the hydrated lime, or in other words NRF was pure limestone. On the basis of a previous study performed in the same laboratory, it was shown that dolomite and calcite were the main minerals in NRF and RF, with the later to show also high percentages of portlandite [34]. The size distribution of both particles is provided in Table 1 .

A 70-100 pengrade binder commonly used in porous asphalt in the Netherlands was selected. The epoxy-based polymer, supplied by ChemCo Systems (California, US), is formulated from two liquid parts; (1) the part A (epoxy resin formed from epichlorohydrin and bisphenol-A) and (2) part B (blend of petroleum asphalt, heavy naphthenic distillate and fatty acid extract). The basic properties of individual parts of epoxy-based polymer are shown in Table 2.

According to the specifications from supplier, part $\mathrm{A}$ and B were oven-heated separately for $1 \mathrm{~h}$, to $85^{\circ} \mathrm{C}$ and $110{ }^{\circ} \mathrm{C}$, respectively. The heated part $\mathrm{A}$ and $\mathrm{B}$ were mixed together for approximately 10 to $20 \mathrm{~s}$ with a weight ratio of 20:80, and the epoxy polymer was produced. Immediately after that, the polymer was mixed further with the already pre-heated unaged 70 -100 pengrade binder at $120{ }^{\circ} \mathrm{C}$ with a weight ratio of 20:80 (EB20), and 50:50 (EB50) of epoxy and neat binder (EB0), respectively. Filler-including samples (EBF0, EBF20, EBF50) were prepared by mixing filler particles with EB binders, produced as described above, with a 56:44 weight ratio of filler and binder. Before mixing filler and binders, RF and NRF were pre-heated in the oven for approximately $60 \mathrm{~min}$ at $120{ }^{\circ} \mathrm{C}$. Mixing fillers and binders performed manually for $5 \mathrm{~min}$ to ensure production of homogeneous mixes without migrated particles at the bottom of can. All the samples were placed in a refrigerator at $-10{ }^{\circ} \mathrm{C}$ to prevent any undesired (curing/aging) reaction.

Table 1 Cumulative percentage passing of NRF and RF particles [34]

\begin{tabular}{llllllllllllllllll}
\hline Particle size $[\mu \mathrm{m}]$ & 0.5 & 1 & 2 & 3 & 4 & 5 & 10 & 25 & 32 & 40 & 45 & 63 & 75 & 90 & 125 & 150 & 180 \\
\hline $\mathrm{NRF}^{\mathrm{a}}$ & 0 & 6.85 & 20.1 & 30.1 & 37.8 & 44.4 & 69.3 & 93.2 & 95.6 & 97.4 & 98.1 & 99.5 & 99.8 & 100 & 100 & 100 & 100 \\
$\mathrm{RF}^{\mathrm{b}}$ & 0 & 9.18 & 26.9 & 39.9 & 49.3 & 56.6 & 76.8 & 94.2 & 96.5 & 98.3 & 99 & 100 & 100 & 100 & 100 & 100 & 100 \\
\hline
\end{tabular}

${ }^{a}$ Density: $2.767 \mathrm{~g} / \mathrm{cm}^{3}$; BET specific surface area: $13.25 \mathrm{~m}^{2} / \mathrm{g}$

${ }^{\mathrm{b}}$ Density: $2.550 \mathrm{~g} / \mathrm{cm}^{3}$; BET specific surface area: $8.51 \mathrm{~m}^{2} / \mathrm{g}$ 
Table 2 Properties of epoxy-based polymer used in the study

\begin{tabular}{ll}
\hline Property & Value \\
\hline Epoxy-based component (Part A) & \\
Viscosity at $25^{\circ} \mathrm{C}[\mathrm{cP}]$ & $11,000-15,000$ \\
Specific gravity at $23{ }^{\circ} \mathrm{C}$ & 1.16 \\
Boiling point $\left[{ }^{\circ} \mathrm{C}\right]$ & $>260$ \\
Asphalt-based component (Part B) & \\
Viscosity at $100{ }^{\circ} \mathrm{C}[\mathrm{cP}]$ & 140 \\
Specific gravity at $25{ }^{\circ} \mathrm{C}$ & 0.99 \\
Boiling point $\left[{ }^{\circ} \mathrm{C}\right]$ & 288 \\
Flash point, Cleveland open cup $\left[{ }^{\circ} \mathrm{C}\right]$ & 232 \\
\hline
\end{tabular}

${ }^{\mathrm{a}}$ Bisphenol-A-epichlorohydrin epoxy resin

${ }^{\mathrm{b}}$ Mix of petroleum asphalt, heavy naphthenic distillate and extract

\subsection{Detachment test method}

In the past, special attention was given to the influence of hydrated lime (RF) on the performance of asphalt. However, the synergetic effect between fillers and epoxy polymers was never examined. In this research, the interfacial bond between the mastic (i.e., EB0, EB20 and EB50 with filler) and the stone surface was studied by using sandstone as stone and two types of fillers. Manufactured stone cylinders together with mastics produce the testing configuration of stonemastic columns.

Regarding the manufacturing of stone columns, cylinders were saw-cut first by using a water-cooled tile saw with a carbide-tipped blade to the disk-shaped sandstone slabs (8-mm diameter). After polishing the top and the bottom surfaces of the cylinders, they were cleaned with deionised water and dried to remove impurities and remaining moisture, respectively. In addition to substrates, mastic at $130{ }^{\circ} \mathrm{C}$ was poured on the one side of substrate, which was preheated at $70{ }^{\circ} \mathrm{C}$. Immediately afterward, another surface at the same temperature was annealed to the exposed face of mastic to form a thin film of $0.015-\mathrm{mm}$ thickness. The operations to form the mastic film between cylinders and to produce the specimens/stone-mastic columns were fully controlled in a DSR device.

To evaluate the influence of the filler types on the stone-mastic adhesive strength and the strength buildup during the polymerization of epoxy in binder, specimens were conditioned in the oven at $130{ }^{\circ} \mathrm{C}$ for
Fig. 1 Detachment test; a Teflon mould designed for storing stone-mastic column during oven-conditioning and b test configuration

two time length (1.5 and $3 \mathrm{~h}$ ). However, to keep the original geometric characteristics of specimens during their conditioning at high temperatures, a Teflon mould was specially designed and manufactured (see Fig. 1a). In this mould, the specimen could be stored at high temperatures allowing also the infiltration of oxygen in them without losing their original geometry. Finally, specimens were mounted in the DSR to perform uniaxial monotonic tensile tests (i.e., detachment tests, see Fig. 1b) and to determine the stonemastic adhesive strength computed as the ratio of the peak load divided by the cross-sectional area of the mastic film between substrates. Three replicate specimens were tested for each conditioning.

\subsection{Chemical compositional and rheology changes}

From the previous section, the NRF was selected for further studies on the aging of epoxy modified asphalt mastic. To simulate in-field aging of a material with long-lasting characteristics, as EBFs, which can have last two or more times longer than a typical asphalt pavement it is suggested to extend the time periods in PAV. For this reason, samples were subjected to PAVaging (NEN-EN 14769) for 20, 40 and $80 \mathrm{~h}$. To be full cured before PAV-aging, the mastics have been conditioned in an oven for $8 \mathrm{~h}$ at $130{ }^{\circ} \mathrm{C}$ to ensure that the epoxy network was crosslinked (reached the gel point [35]) and to avoid any uncontrolled polymerization reaction in PAV due to the high pressure. For consistency reasons, the unmodified asphalt mastic samples were oven conditioned with the same way before PAV aging. Through the oven-conditioning of samples prior to accelerated aging PAV method, no settlement of fillers was noticed, and the samples could be workable enough, even of high viscosity, after $8 \mathrm{~h}$ at $130{ }^{\circ} \mathrm{C}$. After the completion of oven conditioning, hot mastics were stirred manually in the can to ensure the removal bubbles and poured in PAV pans. Also, oven-aging (3.2-mm sample thickness) was performed (1-atm aging) 0, 2, 5, 24, 120, 240 and $480 \mathrm{~h}$ at $130{ }^{\circ} \mathrm{C}$. After each aging period, the chemical and mechanical properties were measured as function 

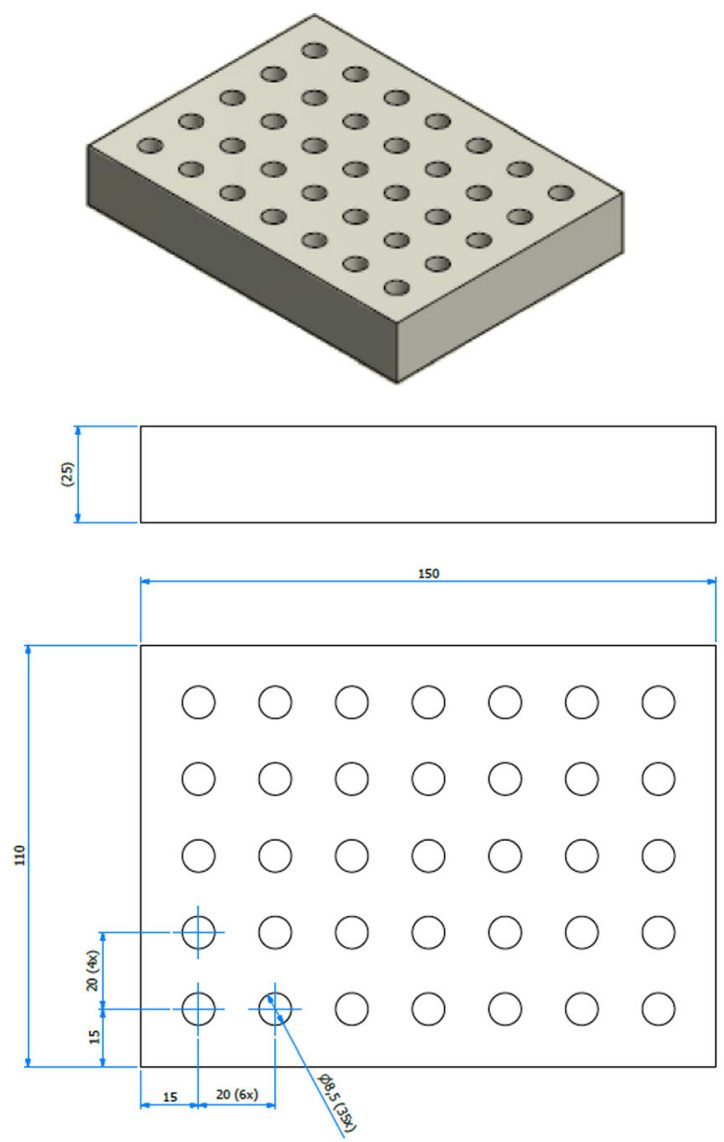

(a)
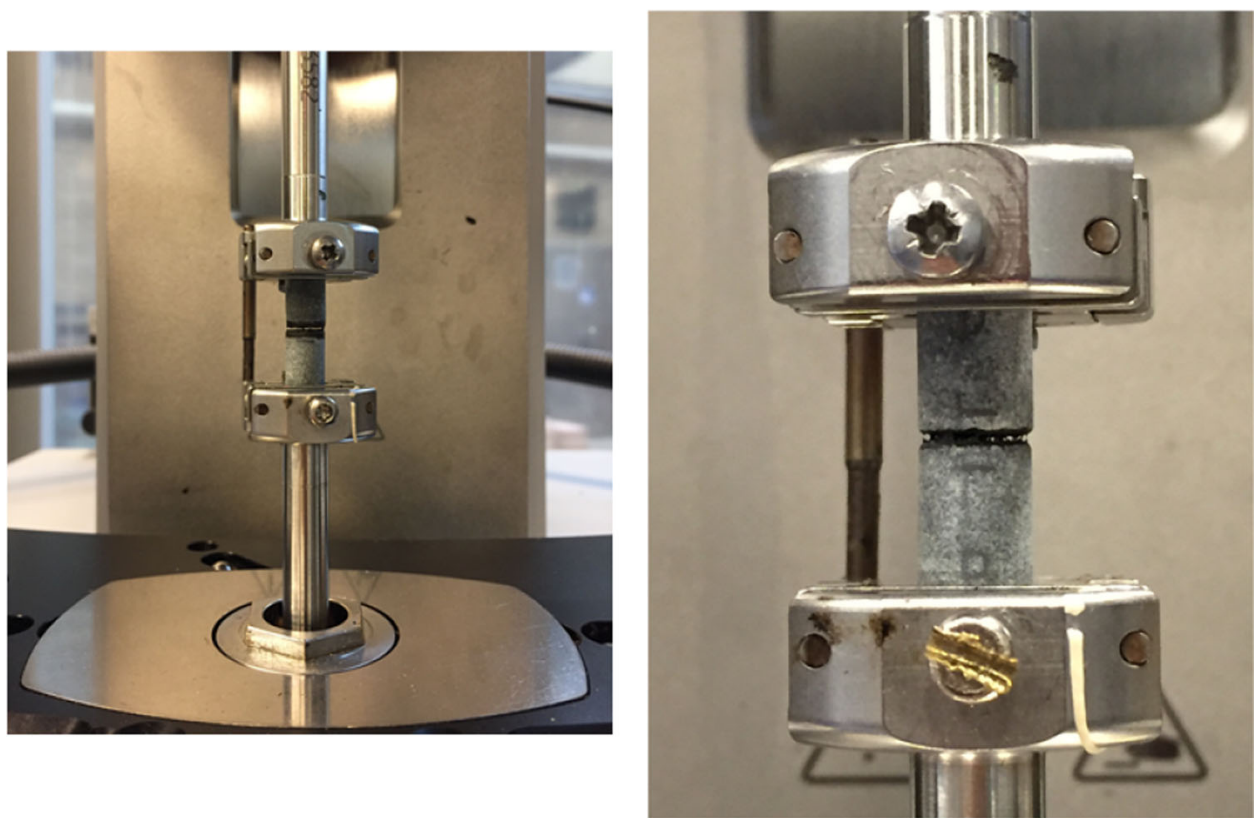

(b) 
of time through two analytical techniques; Fourier Transform Infrared (FT-IR) spectroscopy and Dynamic Shear Rheometer (DSR). Due to the fact that the oxidation rate of asphalt binder is affected by the material chemistry, film thickness and temperature [36], all samples were obtained from the top surface of conditioned materials to avoid measuring samples of different aging levels at different depths.

Oxidation aging causes shifting of the rheological properties (i.e., increase of complex modulus and reduce of phase angle) of binder and this can contribute the deterioration of pavement structures. According to the current state-of-the-art, the mechanistic way of quantifying the effect of aging in asphalt binders is by frequency sweep measurements using DSR. With main purpose to investigate the effect of aging and filler particles, selected from adhesion studies, on the performance of $\mathrm{EB}$, the frequencydependent material properties (i.e., complex shear modulus and phase angle) were determined after different aging times. Frequency sweep measurements $(0.1$ to $10 \mathrm{~Hz})$ were performed at different temperatures ranging from 0 to $50{ }^{\circ} \mathrm{C}$ with temperature steps of $10{ }^{\circ} \mathrm{C}$. The parallel plate testing geometry (plates of 8 -mm diameter with a 2-m sample gap) was used to evaluate the viscoelastic properties of different binders after different time periods. The samples of base binder were tested with the same geometry and master-curves were produced with the time-temperature superposition model to shift all temperatures to a reference temperature of $30{ }^{\circ} \mathrm{C}$.

The evolution of chemical compounds due to EB aging was evaluated with a Perkin-Elmer Spectrum FT-IR spectrometer equipped with an Attenuated Total Reflectance (ATR) fixture. The FT-IR spectra with wavenumber from 4000 to $600 \mathrm{~cm}^{-1}$ were recorded and collected for all the samples. A certain amount of material was placed directly on the ATR crystal pedestal and pressed with a constant force to ensure proper contact to the surface. A minimum of three sub-samples was investigated for each sample and 20 scans per sub-sample were performed with a fixed instrument resolution of $4 \mathrm{~cm}^{-1}$. Carbonyl and sulfoxide compounds, typically used as aging indices of asphalt binders $[15,16]$, were calculated by using the area method. The calculation is performed by dividing the area under a specific location of spectrum by the sum of other specific areas. However, carbonyl groups (i.e., carbonyl acid, carbonyl ether and ester) play an important role in the epoxy polymerization in asphalt as well [3, 6, 37]. EBs contain more carbonyls and less sulfoxides than unmodified binders and hence the carbonyls have been excluded from this research. The effect of fillers on the oxidative aging is evaluated based on the evolution of sulfoxides over different aging time periods as in [6]. Sulfoxides are defined as the integrated peak area from 1047 to $995 \mathrm{~cm}^{-1}$.

\section{Results and discussion}

\subsection{Effect of filler type on Stone-Asphalt Binder Adhesion}

Detachment results under uniaxial displacement (0.006- $\mathrm{mm} / \mathrm{s}$ displacement rate) at $20{ }^{\circ} \mathrm{C}$ after increasing epoxy polymerization time phases are presented in Fig. 2. In this figure, it is shown that the ability of EBF0, EBF20 and EBF50 to build-up interfacial bonding (adhesive strength) with sandstone is similar for both filler types (i.e., RF and NRF). However, weakening of interfacial bonding is noticed when RFs are used for EBF20. With RF, lower adhesive strength was obtained than with NRF-EB20 (see Fig. 2a). This is probably cause by the competitive interaction of epoxy-based polymer and RF. Nevertheless, the effect of filler reactivity is minimum in EBF50, most possibly due to the higher amount of epoxy and thus its dominant role on the stone-mastic bond formation.

The adhesion between binder and minerals develops mainly because non-uniformly distributed polar moieties in binder attract oppositely charged polar compounds on the surface of minerals [38]. In case of hydrated lime, fillers are added in binder to react chemically with specific asphaltic functionalities (i.e., carboxylic acids) and to form insoluble calcium-based salts to promote adhesion [39]. However, carboxylic acids are included in epoxy-based polymer as well and operate as catalysts for the epoxy polymerization. Therefore, two competitive chemical reactions take place from 0 to $3 \mathrm{~h}$ at $130{ }^{\circ} \mathrm{C}$; (a) the epoxy polymerization in binder and (b) the formation of hydrogen bonds between carboxylic acids and calcium-based salts. This competition to prevents epoxy to crosslink in asphalt binder, so the asphaltic film is softened since the epoxy stays in a liquid state and weakening of mastic-aggregate adhesion bond occurs. Large amount of calcium-based salts may be formed 

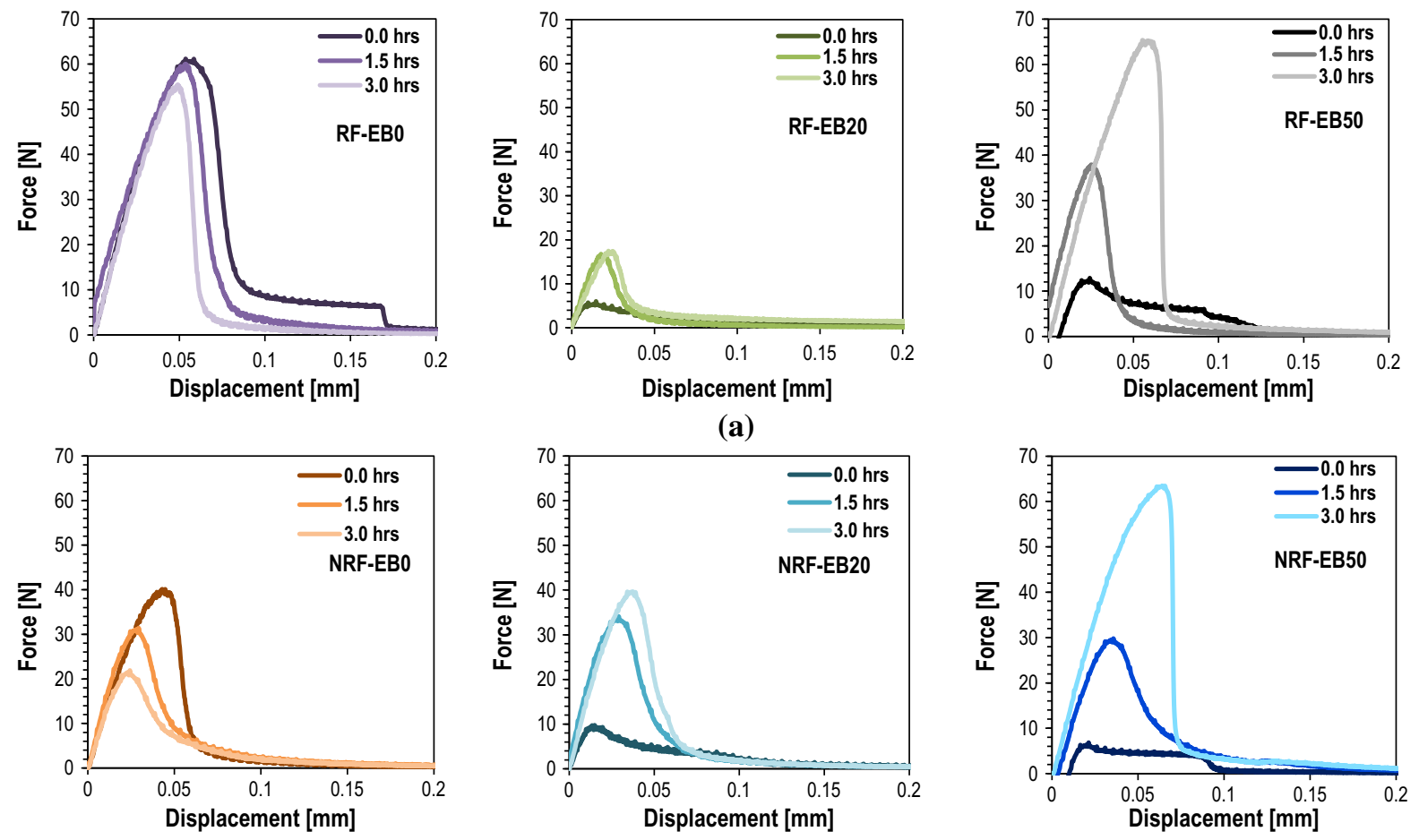

Fig. 2 Representative tensile force versus displacement curves during detachment testing of: a RF and $\mathbf{b}$ NRF filler-including asphalt binder, after different polymerization times at $130{ }^{\circ} \mathrm{C}$ (Tests at $20{ }^{\circ} \mathrm{C}$ and $0.006 \mathrm{~mm} / \mathrm{s}$ displacement rate)

after the reaction of carboxylic acids with hydrate lime hindering thus the polymerization of epoxy system. In other words, the carboxylic acids, which are included in part B of epoxy binder, may also react directly with the hydrate lime and thus not enough acids are available to crosslink the epoxy resin (i.e., part A). Another explanation of the weakening mechanism is that, free calcium ions from the surface of the hydrated lime may be dispersed in binder as well contributing further to bond weakening, due to the fact that the hydrated lime did not react fully with the available acidic functionalities. On the other hand, the use of NRF particles in EB20 resulted in a film layer of higher adhesive strength than the RF-treated EB20 (see Fig. 3) and a stable strength build-up during polymerization. The low reactivity of filler particles allowed the undisrupted epoxy polymerization, when it is used at lower modification levels, and the formation of a high strength adhesive layer between the stone columns.

Additionally, the slightly higher mean value of strength of NRF-EB0 (0.70 MPa) than of NRF-EB20 $(0.49 \mathrm{MPa})$ after $3 \mathrm{~h}$ of oven conditioning possibly occur due to the incomplete curing of epoxy component in asphalt. As have been noticed in earlier studies $[35,40]$, when the volume of asphalt binder is higher than that of epoxy, higher energy demands are needed to initiate the epoxy polymerization reactions, or the curing requires longer time periods under the same energy conditions. This can be confirmed by the rate of strength evolution in NRF-EB50 and RF-EB50 as well. Regarding the effect of epoxy modification in asphalt mastic with the NRF particles, the mean value of adhesion strength of NRF-EB50 (0.87 MPa) was slightly higher than of NRF-EB0 (0.70 MPa), after $3 \mathrm{~h}$ of oven conditioning, but of high standard deviation errors. Thus, a significant statistical different was apparent when the adhesion strength of epoxy modified mastics was assessed with the highest measured strength of $3 \mathrm{~h}$ cured NRF-EB50 to be $1.26 \mathrm{MPa}$ in comparison with the maximum value of strength of NRF-EB0 (0.78 MPa). Moreover, it should be mentioned that hydrated lime is mainly used in asphalt binder to form hydrophobic insoluble salts, after reacting with endogenous carboxylic acids in the binder, which help to increase the material resistance 


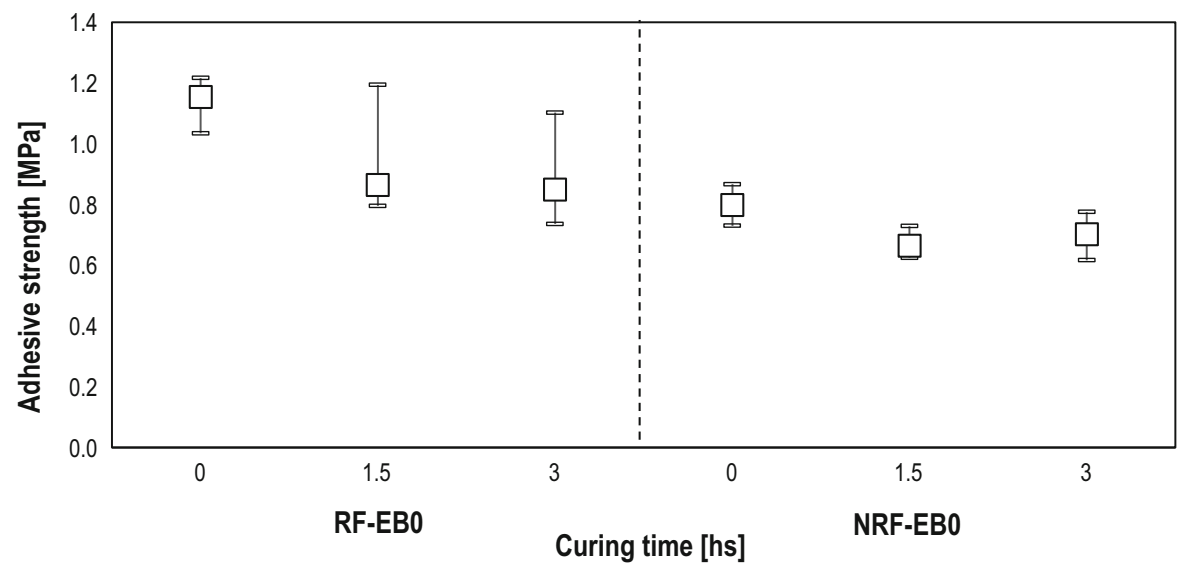

(a)

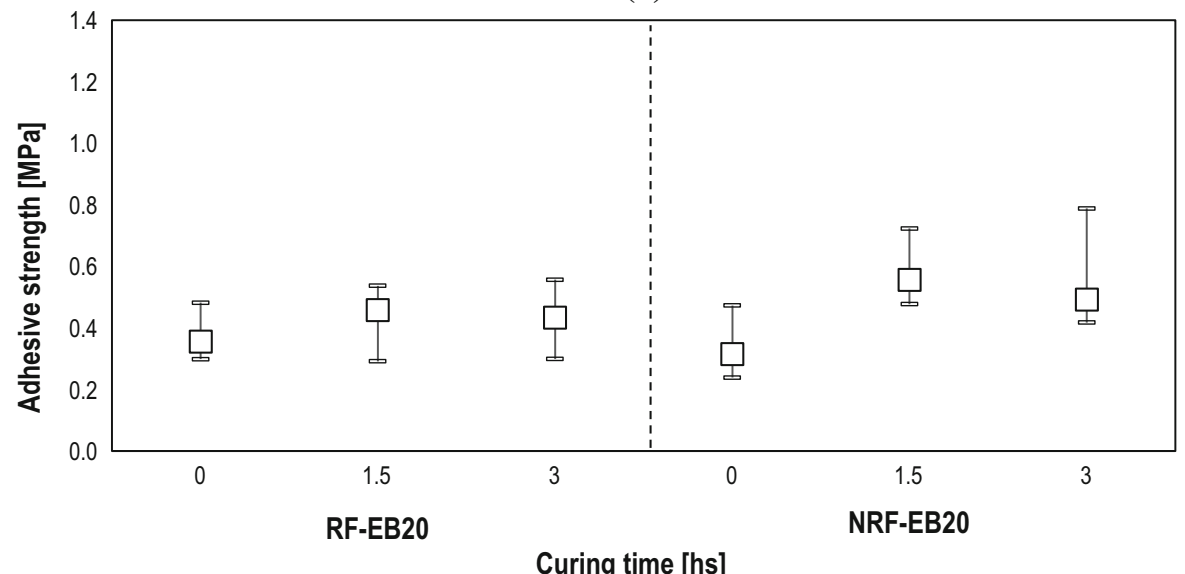

(b)

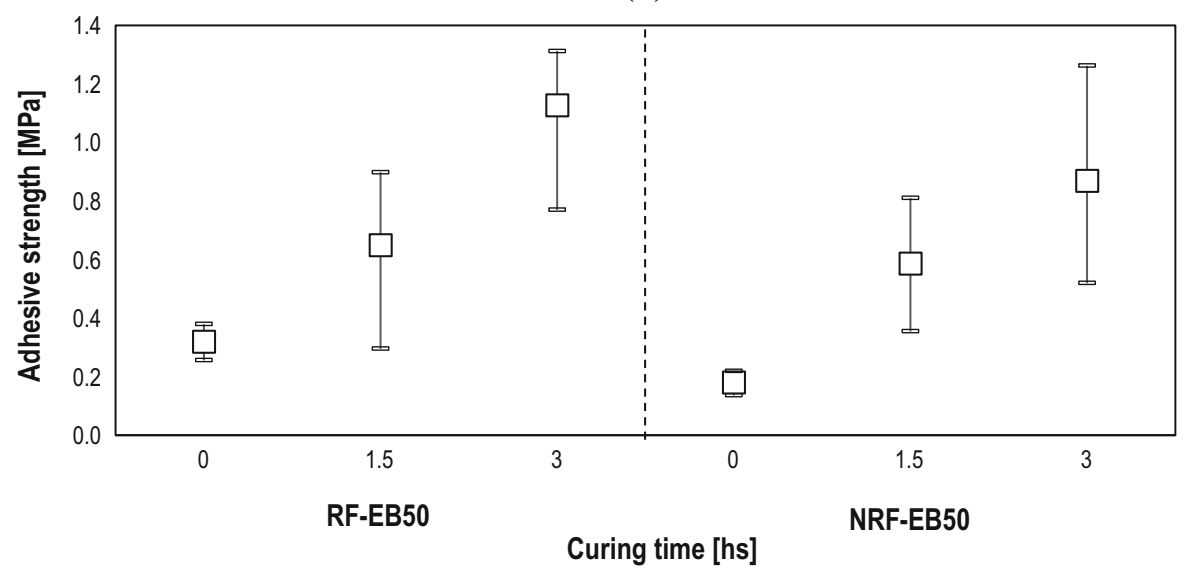

(c)

Fig. 3 Adhesive strength evolution with stone surface of mastic of a EB0, b EB20 and c EB50 with RF and NRF (at $20{ }^{\circ} \mathrm{C}$ and $0.006 \mathrm{~mm} / \mathrm{s}$ displacement rate)

against oxygen. In this study, by exploring the impact of filler reactivity in the epoxy polymerization, it was noticed also that the neat binders with hydrated lime had a lower detrimental effect on their debonding behaviour after oven-conditioning at $130{ }^{\circ} \mathrm{C}$ compared with the binders with a non-reactive type of 
filler. This observation is in agreement with previous studies reporting the benefits of reduced aging rates in hydrated lime treated asphaltic materials [25, 26]. Nevertheless, the adhesion bonding increased strongly with the addition of epoxy polymer in the asphalt binder and based on this result the best performing filler type (i.e., NRF) with epoxy was selected to be used for the aging studies of EBFs in the next section.
5.2 Effect of epoxy modification on aging asphalt mastic

Figure $4 a, b$ show the evolution of sulfoxides as function of aging time of EBFs after PAV and oven aging, respectively. In Fig. 4a, the PAV aging performance of the materials is shown after 20, 40 and $80 \mathrm{~h}$. The amount of sulfoxide compounds in EBFs did not increase dramatically when the PAV-aging was extended to 40 and $80 \mathrm{~h}$. Further, after oven-aging,
Fig. 4 Relationship of sulfoxide $(\mathrm{S}-\mathrm{O})$ and time in a PAV at $100{ }^{\circ} \mathrm{C}$ and $\mathbf{b}$ oven at $130{ }^{\circ} \mathrm{C}$ for studied materials

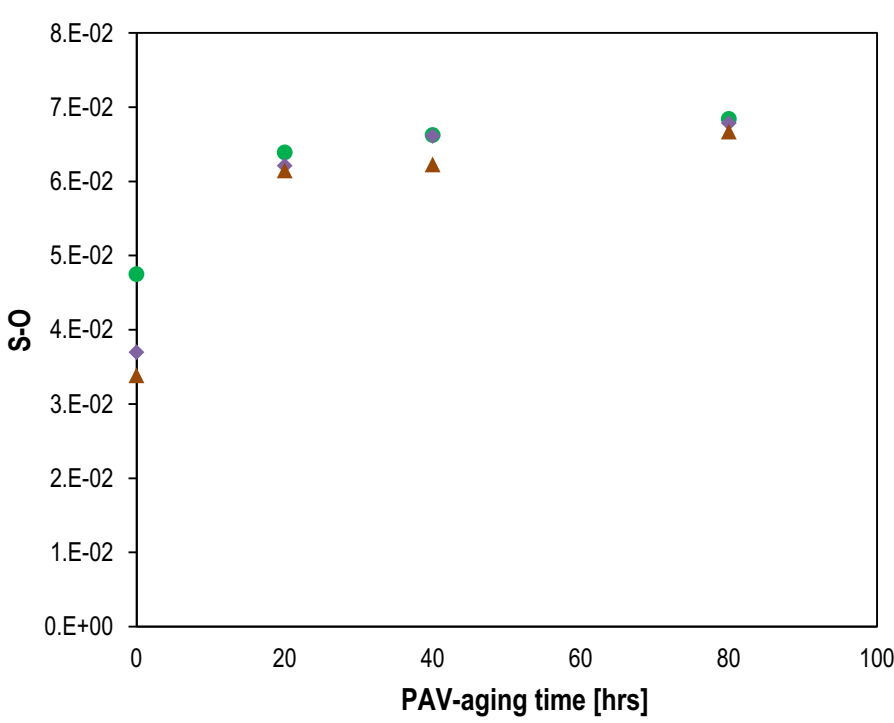

(a)

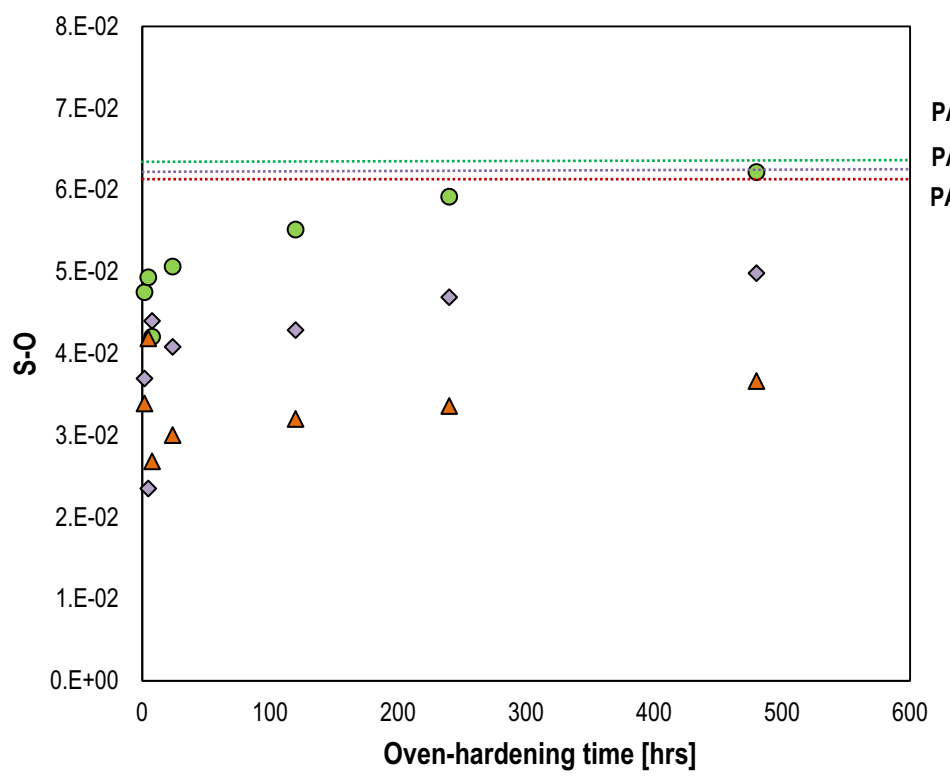

(b)
- EBFO

- EBF20

$\triangle$ EBF50
PAV-20hrs aged EBFO

PAV-20hrs aged EBF20 PAV-20hrs aged EBF50

O EBFO

$\checkmark$ EBF20

$\triangle$ EBF50 
Fig. 5 Master curves of complex modulus and phase angle of studied materials after a PAV-aging for different times and $\mathbf{b}$ ovenaging for different times; (i) $\mathrm{EBF} 0$, (ii) $\mathrm{EB} 2 \mathrm{F0}$, and (iii) EBF50

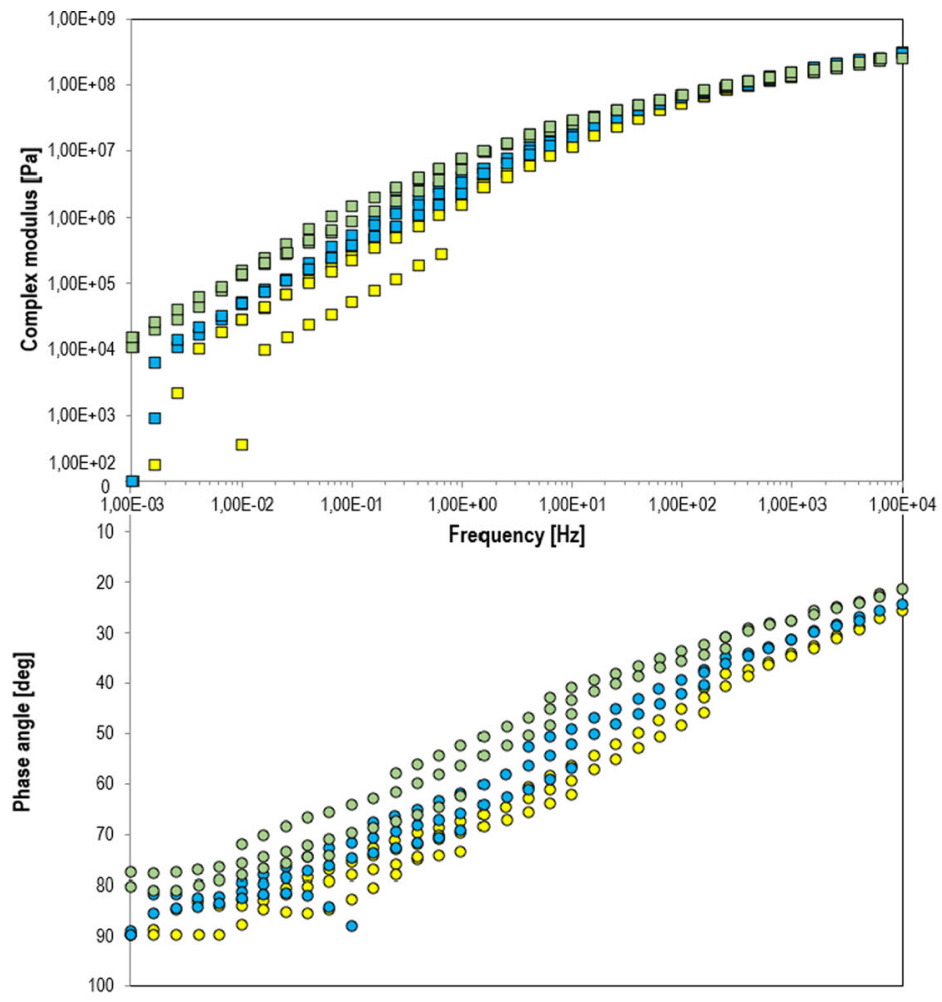

$\square$ PAV-20hrs

$\square$ PAV-40hrs

$\square$ PAV-80hrs

O PAV-20hrs

O PAV-40hrs

O PAV-80hrs

(i)

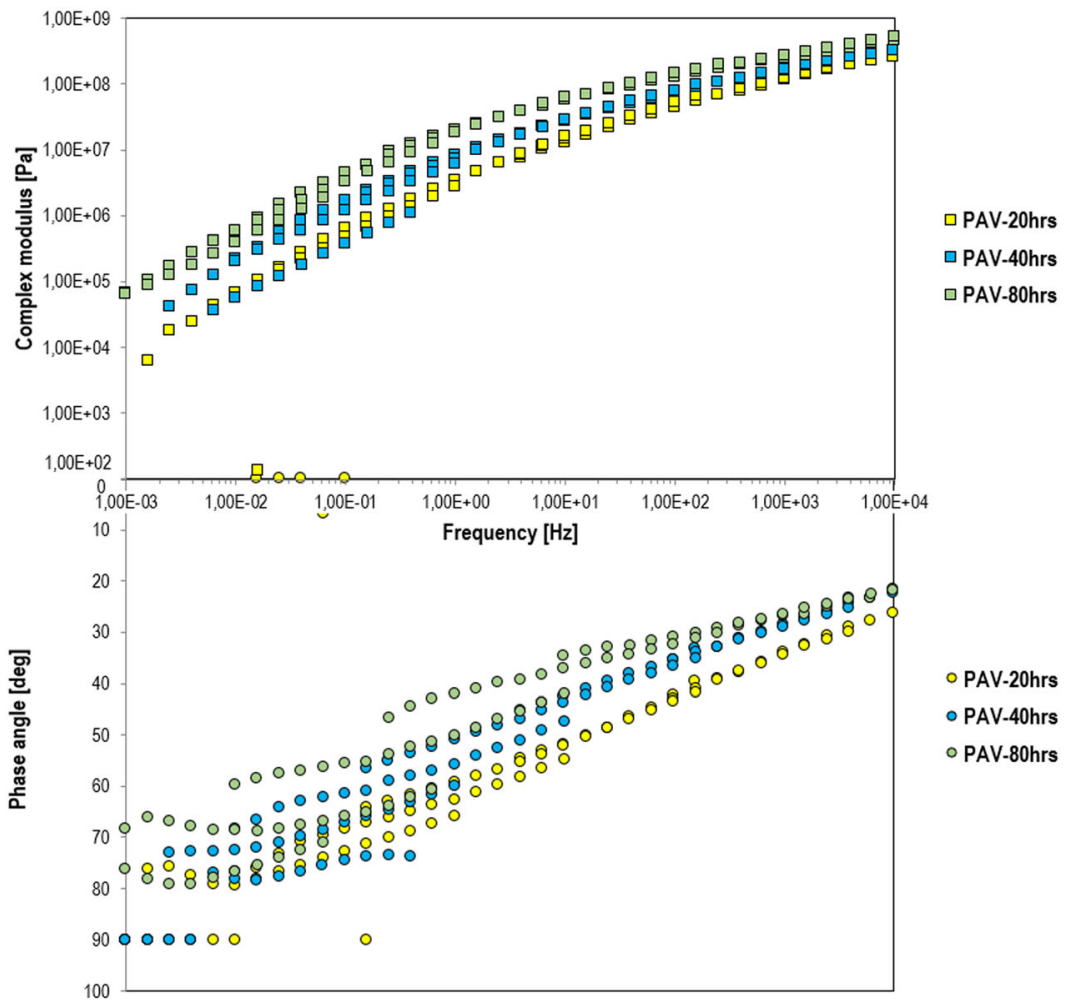

(ii) 
Fig. 5 continued

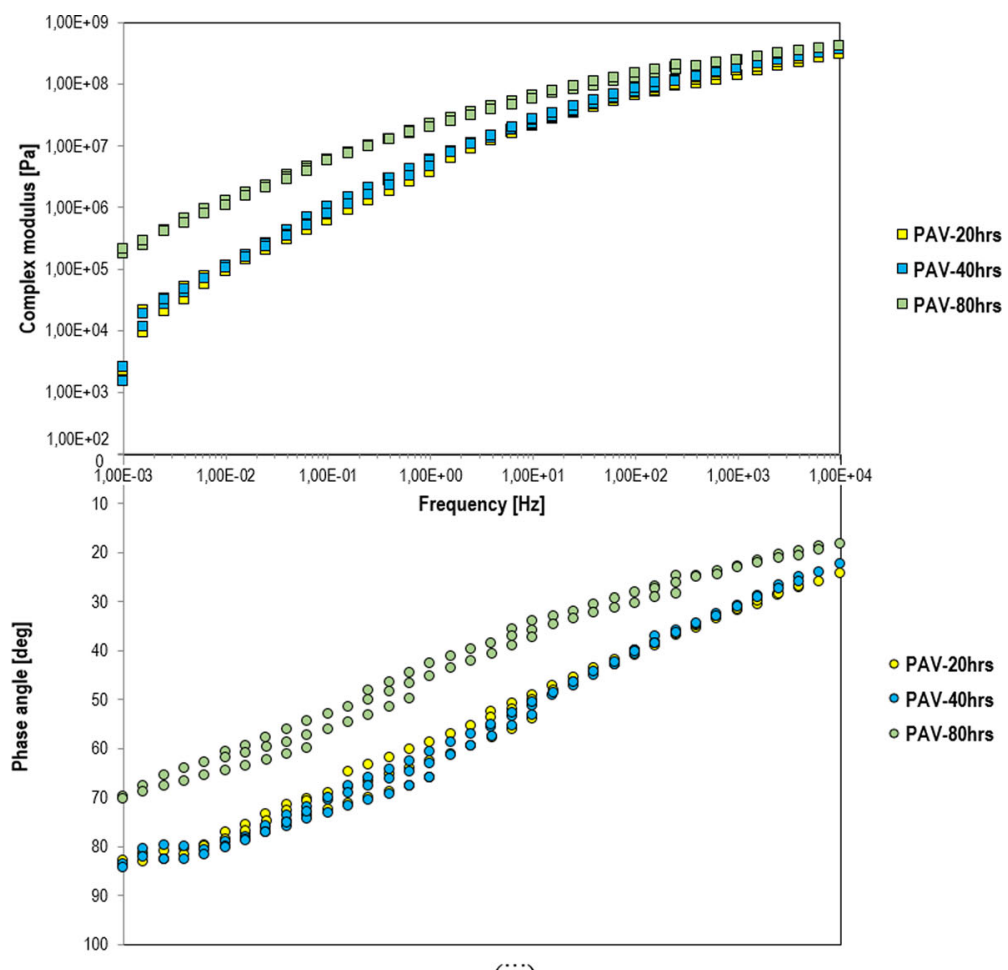

(iii)

(a)

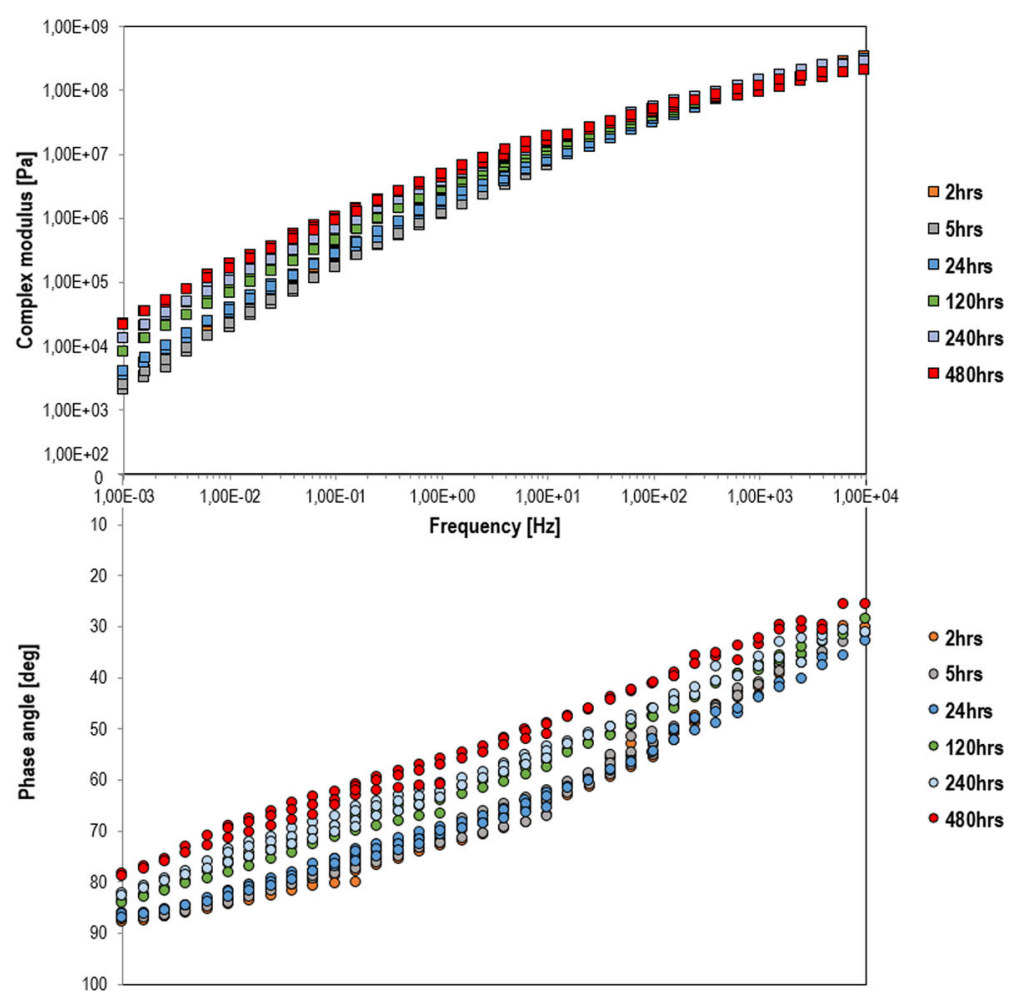

(i) 
Fig. 5 continued
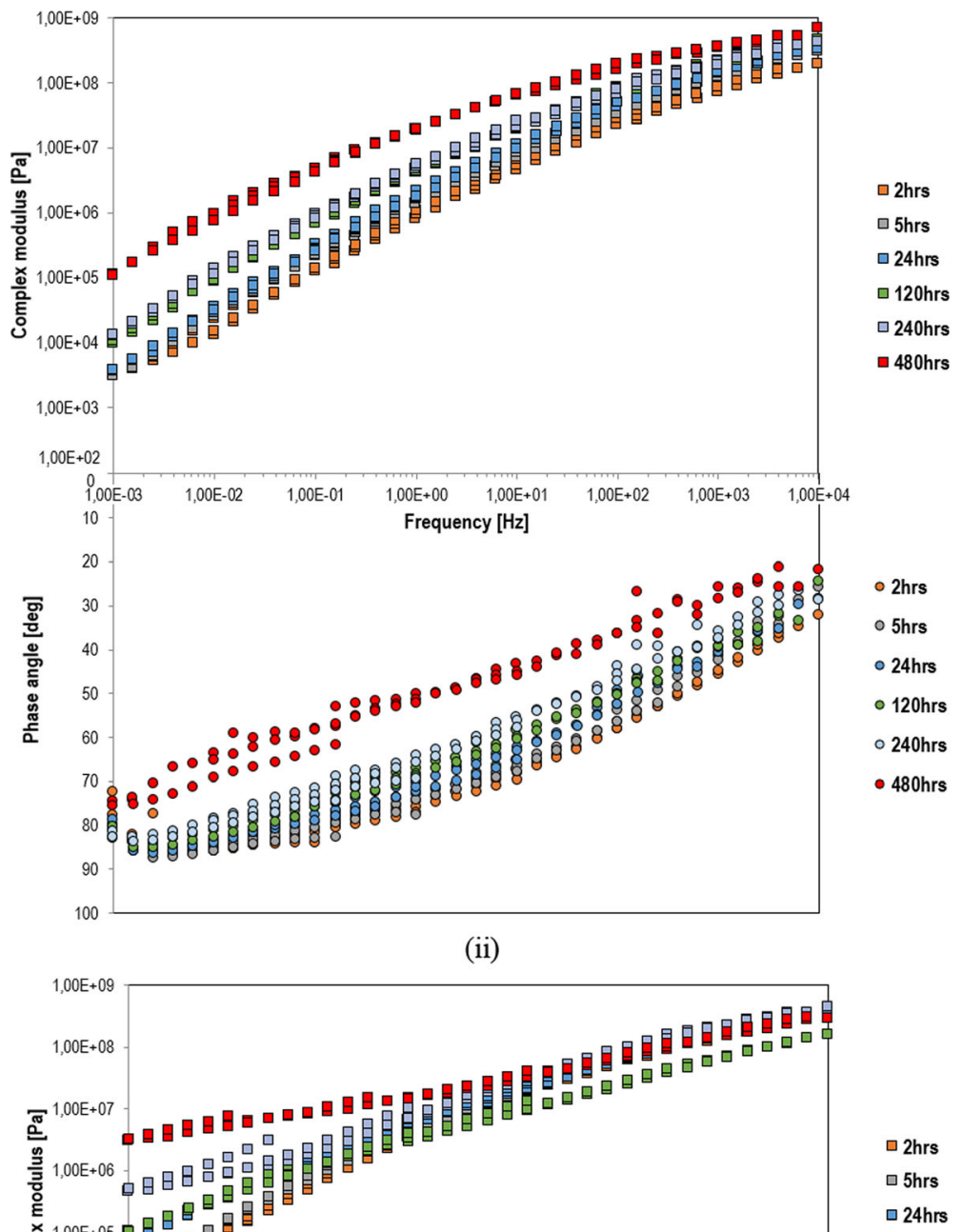

$\square 2 \mathrm{hrs}$

$\square 5 \mathrm{hrs}$

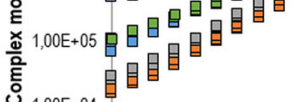

$\square 24 \mathrm{hrs}$

$\square 120 \mathrm{hrs}$

$\square 240 \mathrm{hrs}$

$\square 480 \mathrm{hrs}$

$1,00 E+03$

$1,00 E+02$

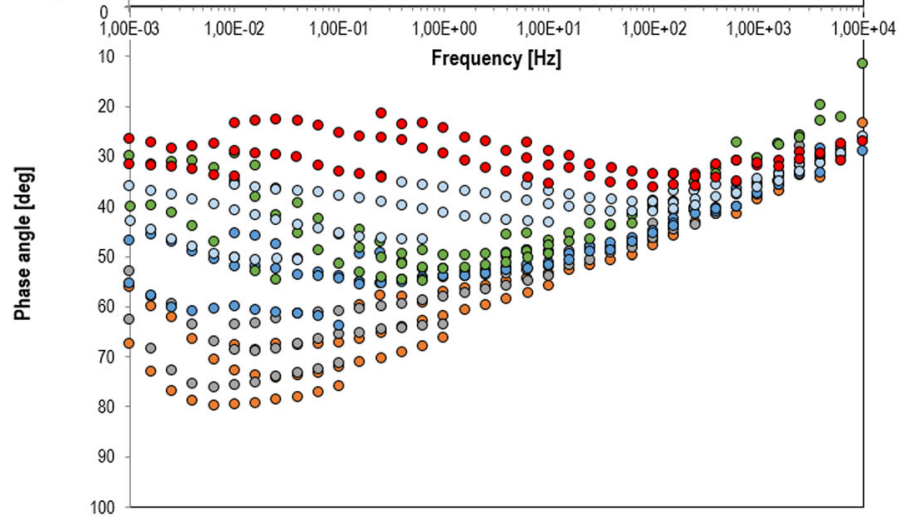

(iii)

(b) 
sulfoxides of NRF-including asphalt binder (EBF0) increased more rapidly than the epoxy modified materials. Consequently, higher epoxy modification levels resulted in lower sulfoxides with EBF50 showing the lowest amount of sulfoxide at the same aging time periods. As noted in [3, 6, 37], the studied epoxy-based polymer is composed of carbonyls with low concentration of sulphur compounds. Thus, by substituting mass of asphalt binder with epoxy, new blends of higher carbon and lower sulphur type compounds are formulated (volume additivity theory). For EBF0, sulfoxide compounds generated after $20 \mathrm{~h}$ PAV-aging were almost equivalent to oven-aging at $130{ }^{\circ} \mathrm{C}$ for $480 \mathrm{~h}$ (Fig. 4b). However, this is not valid for EBF20 and EBF50 which did not show identical sulfoxides after oven and PAV aging. Nevertheless, it is obvious from these graphs that the reaction rate is lower but the same tendency can be observed when the epoxy is added in a mastic. As in [6], it seems that the sulfoxide content of EB systems can be an effective way to describe their oxidative aging behavior at $130{ }^{\circ} \mathrm{C}$ (temperatures above $100{ }^{\circ} \mathrm{C}$ ).

The mechanical performance of epoxy-based polymers is time- and temperature-dependent similar as asphalt binders. When epoxy-based polymers are used as modifiers in binder, a two-phase system is formed and it becomes a three-phase material with the addition of filler particles. The behaviour of three phase EBFs can be explained only when both (uncrosslinked) epoxy and binder are considered as a liquid, of which one of the two serves as the matrix, and then fillers are a third solid phase.

Comparison of the time-dependent performance of EB as shown in [6], confirms that the inclusion of fillers causes a totally different viscoelastic behaviour between the base and the modified binder. Figure $5 \mathrm{a}$ shows the master-curves of complex modulus and phase angle of PAV-aged mastics with different epoxy modification levels over aging time. The influence of aging on the mechanics of EB mastics is apparent and the complex modulus increases rapidly with PAVaging time. In addition to PAV-aging, results after increasing oven-aging times are shown in Fig. 5b. In both PAV- and oven-aging, the modulus tends to merge together to the same values at higher frequencies with EBF50 stiffer than EBF20 and EBF0 at the same aging conditions. Furthermore, as discussed in [6], the phase angle was more sensitive to chemical changes than the modulus of EBs, and the phase angle master-curves are not as straight forward as the complex modulus ones. With increasing PAV- and oven-aging times, the phase angle decreases and thus EBFs becomes more elastic as shown in Fig. 5a, b mainly due to the presence of epoxy-based polymer in the mastic. Overall, by comparing the master-curves of samples aged with oven and PAV (Fig. 5a versus b), the rate of change of viscoelastic response (i.e., increase of modulus and decrease of phase angle) of EBFs subjected to PAV was faster than the oven aged one, mainly due to the influence of pressure in PAV.

\section{Conclusions}

As mentioned before, this research was designed to explore the effect of epoxy modification on the aging resistance of asphalt mastics. Hydrated lime is widely used as filler/agent to improve the durability of asphalt binders, so first special emphasis was given on the synergy between epoxy and hydrated lime in asphalt. Detachment tests (adhesion between stone and mastic) were performed during the polymerization phase of epoxy in mastic showing that the incorporation of reactive particles in epoxy modified mastics blocks the crosslinking of the epoxy-based network in binder. Competitive chemical reactions take place between the hydrated lime (i.e., RF) and the carboxylic acids, which normally are added to catalyse the crosslinking of epoxy polymer. This interaction led to the inefficient epoxy polymerization, and thus part of it remains uncured at liquid state. The reaction between these two components decreased the bonding of mastic with stone aggregates, and thus, the pure limestone fillers were selected for the aging studies since they demonstrated a neutral effect on epoxy polymerization. Finally, from the aging results, the epoxy modified mastics have shown very high resistance against viscous flow, or more elastic response. Less sulfoxides formed and higher modulus levels were measured with increasing the epoxy polymer in mastics over ovenand PAV-aging conditions. Due to the pressure difference, the rate of modulus increases and phase angle decrease was higher when the materials were conditioned in PAV than in oven.

Acknowledgements Financial support from the Province of Noord Holland on Epoxy modified Asphalt Concrete project is 
gratefully acknowledged. The authors thank ChemCo Systems for supplying the epoxy-asphalt binder.

\section{Compliance with ethical standard}

Conflict of interest The authors declare that they have no conflict of interest.

Open Access This article is licensed under a Creative Commons Attribution 4.0 International License, which permits use, sharing, adaptation, distribution and reproduction in any medium or format, as long as you give appropriate credit to the original author(s) and the source, provide a link to the Creative Commons licence, and indicate if changes were made. The images or other third party material in this article are included in the article's Creative Commons licence, unless indicated otherwise in a credit line to the material. If material is not included in the article's Creative Commons licence and your intended use is not permitted by statutory regulation or exceeds the permitted use, you will need to obtain permission directly from the copyright holder. To view a copy of this licence, visit http://creativecommons.org/licenses/by/4.0/.

\section{References}

1. Youtcheff J, Gibson N, Shenoy A, Al-Khateeb G (2006) The evaluation of epoxy asphalt and epoxy asphalt mixtures. In: Proceedings of the Canadian Technical Asphalt Association 51

2. Widyatmoko I, Zhao B, Elliott RC, Lloyd WG (2006) Curing characteristics and the performance of epoxy asphalts. In: Proceedings of the Canadian Technical Asphalt Association 51

3. Herrington P, Alabaster D (2008) Epoxy modified opengraded porous Asphalt. Road Mater Pavement Des 9(3):481-498

4. Luo S, Lu Q, Qian Z (2015) Performance evaluation of epoxy modified open-graded porous asphalt concrete. Constr Build Mater 79:97-102

5. Wu JP, Herrington PR, Alabaster D (2019) Long-term durability of epoxy-modified open-graded porous asphalt wearing course. Int J Pavement Eng 20(8):902-927

6. Apostolidis P, Liu X, Erkens S, Scarpas A (2019) Evaluation of epoxy modification in bitumen. Constr Build Mater 208:361-368

7. Chen C, Eisenhut WO, Lau K, Buss A, Bors J (2020) Performance characteristics of epoxy asphalt paving material for thin orthotropic steel plate. Int $\mathrm{J}$ Pavement Eng 21(3):397-407

8. Gaul RW (1996) Epoxy asphalt concrete-a polymer concrete with 25 years' experience. Am Concr Inst Publ Symp 166(13):233-251

9. Lu Q, Bors J (2015) Alternate uses of epoxy asphalt on bridge decks and roadways. Constr Build Mater 78:18-25

10. International Transport Forum (2017) Long-life surfacings for roads: field test results. ITF Research Reports, OECD, Paris, France

11. Zegard A, Smal L, Naus R, Apostolidis P, Liu X, van de Ven MFC, Erkens S, Scarpas A (2019) Long-lasting surfacing pavements using epoxy asphalt: province of North Holland Case Study. In: Transportation Research Board (TRB) 98th Annual Meeting, Washington D.C.

12. Apostolidis P, Liu X, Erkens S, Scarpas A (2020) Use of epoxy asphalt as surfacing and tack coat material for roadway pavements. Constr Build Mater 250:118936

13. Dinnen J, Farrington J, Widyatmoko I (2020) Experience with the use of epoxy-modified bituminous binders in surface courses in England. Asphalt Professional, pp 14-21

14. Branthaver JR, Petersen JC, Robertson RE, Duvall JJ, Kim SS, Harnsberger PM, Mill T, Ensley EK, Barbour FA, Schabron JR (1993) Binder characterization and evaluation-volume 2: chemistry. SHRP Report A-368. Strategic Highway Research Program, National Research Council, Washington, D.C.

15. Petersen JC, Branthaver JF, Robertson RE, Harnsberger PM, Duvall JJ, Ensley EK (1993) Effects of Physicochemical Factors on Asphalt Oxidation Kinetics. In Transportation Research Record 1391, TRB, National Research Council, Washington, D.C., pp 1-10

16. Petersen JC, Harnsberger PM (1998) Asphalt aging: dual oxidation mechanism and its interrelationships with asphalt composition and oxidative age hardening. In: Transportation Research Record 1638, TRB, National Research Council, Washington, D.C., pp 47-55

17. Apostolidis P, Liu X, Kasbergen C, Scarpas A (2017) Synthesis of asphalt binder aging and the state of the art of antiaging technologies. In: Transportation Research Record 2633, TRB, National Research Council, Washington, D.C., 2017, pp 147-153

18. Hanson DI, Graves RE, Brown ER (1994) Laboratory evaluation of the addition of lime treated sand to hot-mix asphalt. In: Transportation Research Record 1469, TRB, National Research Council, Washington, D.C., pp 34-42

19. Moraes R, Velasquez R, Bahia HU (2011) Measuring the effect of moisture on asphalt-aggregate bond with the bitumen bond strength test. In: Transportation Research Record 2209, TRB, National Research Council, Washington, D.C., pp 70-81

20. Craus J, Ishai I, Sides A (1978) Some physico-chemical aspects of the effect and the role of the filler in bituminous paving mixtures. J Asphalt Paving Technol 47:558-588

21. Bahia HU, Anderson DA, Christensen DW (1992) The bending beam rheometer: a simple device for measuring low-temperature rheology of asphalt binders. J Assoc Asphalt Paving Technol 61:117-148

22. Anderson DA, Christiansen DW, Bahia HU, Dongre R, Sharma MG, Antle CE, Button J (1993) Binder characterization and evaluation. SHRP Project A-002A Final Report. Strategic Highway Research Program, National Research Council, Washington, D.C.

23. Rodriguez MG, Morrison GR, Van Loon JR, Hesp SAM (1995) Low-temperature failure in particulate-filled asphalt binders and asphalt concrete mixes. J Assoc Asphalt Paving Technol 69:159-187

24. Lesueur D, Dekker DL, Planche J-P (1995) Comparison of carbon black from pyrolized tires to other fillers as asphalt rheology modifiers. In: Transportation Research Record 1515, TRB, National Research Council, Washington, D.C., pp 47-55 
25. Plancher H, Green EL, Petersen JC (1976) Reduction of oxidative hardening of asphalts by treatment with hydrated lime-a mechanic study. J Assoc Asphalt Paving Technol 45:1-24

26. Petersen JC, Plancher H, Harnsberger PM (1987) Lime treatment of asphalt to reduce age hardening and improve flow properties. J Assoc Asphalt Paving Technol 56:632-653

27. Johansson L, Branthaver JF, Robertson RE (1995) A study of rheological properties of lime treated paving asphalts aged at $60^{\circ} \mathrm{C}$ in a pressure aging vessel. Fuel Sci Technol Int 13(10):1317-1343

28. Johansson L, Branthaver JF, Robertson RE (1996) The influence of metal-containing compounds on enhancement and inhibition of asphalt oxidation. Fuel Sci Technol Int 14(8):1143-1159

29. Elder AC, Hatting MM, Servas VP, Marais CP (1985) Use of aging tests to determine the efficiency of hydrated lime additions to asphalt in retarding its oxidative hardening. J Assoc Asphalt Paving Technol 54:118-139

30. Lesueur D, Little DN (1999) Effect of hydrated lime on rheology, fracture, and aging of bitumen. In: Transportation Research Record 1661, TRB, National Research Council, Washington, D.C., pp 93-105

31. Huang S-C, Petersen JC, Robertson RE, Branthaver JF (2002) Effect of hydrated lime on long-term oxidative aging characteristics of asphalt. In: Transportation Research Record 1810, TRB, National Research Council, Washington, D.C., pp. 17-24

32. Petersen JC, Barbour FA, Dorrence SM (1974) Catalysis of asphalt oxidation by mineral aggregate surfaces and asphalt components. J Assoc Asphalt Paving Technol 43:162-177

33. Curtis CW, Ensley K, Epps J (1993) . Fundamental properties of asphalt-aggregate interactions including adhesion and absorption. Strategic Highway Research Program: Report No. SHRP-A-341, National Research Council, Washington, D.C.

34. Mastoras P (2019) Effect of mineral fillers on ageing of bituminous mixtures. M.Sc. Thesis, Delft University of Technology

35. Apostolidis P, Liu X, Kasbergen C, van de Ven MFC, Pipintakos G, Scarpas A (2018) Chemo-rheological study of hardening of epoxy modified bituminous binders with the finite element method. In: Transportation Research Record 2672(28), TRB, National Research Council, Washington, D.C., pp 190-199

36. Herrington PR (2012) Diffusion and reaction of oxygen in bitumen films. Fuel 94:86-92

37. Wei J, Zhang Y (2012) Study on the curing process of epoxy asphalt. J Test Eval 40(7):1-8

38. Robertson RE (2000) Transportation research circular 499: chemical properties of asphalts and their effects on pavement performance. TRB, National Research Council, Washington, D.C

39. Plancher H, Dorrence S, Petersen JC (1977) Identification of chemical types in asphalts strongly absorbed at the asphaltaggregate interface and their relative displacement by water. J Assoc Asphalt Paving Technol 46:151-175

40. Apostolidis P, Liu X, Erkens S, Scarpas A (2020) Characterization of epoxy-asphalt binders by differential scanning calorimetry. Constr Build Mater 249:118800

Publisher's Note Springer Nature remains neutral with regard to jurisdictional claims in published maps and institutional affiliations. 